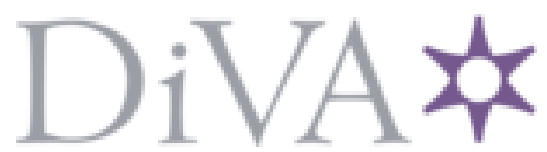

http://www.diva-portal.org

This is the published version of a paper published in International journal of food properties.

Citation for the original published paper (version of record):

Slettengren, K., Xanthakis, E., Ahrné, L., Windhab, E J. (2016)

Flow Properties of Spices Measured with Powder Flow Tester and Ring Shear Tester-XS

International journal of food properties, 19(7): 1475-1482

https://doi.org/10.108o/10942912.2015.1083576

Access to the published version may require subscription.

N.B. When citing this work, cite the original published paper.

Permanent link to this version:

http://urn.kb.se/resolve?urn=urn:nbn:se:ri:diva-331 


\section{Flow Properties of Spices Measured with Powder Flow Tester and Ring Shear Tester-XS}

\section{Katarina Slettengren, Epameinondas Xanthakis, Lilia Ahrné \& Erich J. Windhab}

To cite this article: Katarina Slettengren, Epameinondas Xanthakis, Lilia Ahrné \& Erich J. Windhab (2016) Flow Properties of Spices Measured with Powder Flow Tester and Ring Shear Tester-XS, International Journal of Food Properties, 19:7, 1475-1482, DOI: 10.1080/10942912.2015.1083576

To link to this article: https://doi.org/10.1080/10942912.2015.1083576

(2) Copyright (c) Taylor \& Francis Group, LLC

Accepted author version posted online: 11
Sep 2015.

Published online: 07 Mar 2016.

Submit your article to this journal $\pi$

Џ Article views: 700

View Crossmark data $₫$

Citing articles: 5 View citing articles 


\title{
Flow Properties of Spices Measured with Powder Flow Tester and Ring Shear Tester-XS
}

\author{
Katarina Slettengren ${ }^{1}$, Epameinondas Xanthakis ${ }^{2}$, Lilia Ahrné ${ }^{2}$, and Erich J. Windhab ${ }^{1}$ \\ ${ }^{1}$ Food Process Engineering, Institute of Food Nutrition and Health, ETH Zurich, \\ Schmelzbergstrasse, Zurich, Switzerland \\ ${ }^{2}$ Process and Technology Development, SP Food and Bioscience, Gothenburg, Sweden
}

\begin{abstract}
Due to the importance of powder flow properties and the variety of available measuring methods, several studies were published regarding the comparison of different flow properties testers. Within this work, a ring shear tester from Dr. Dietmar Schulze and a powder flow tester from Brookfield Engineering Laboratories Inc. were compared for cumin (Cuminum cyminum L.), oregano (Origanum vulgare), and onion (Allium cepa) powder and granules. The spices showed similar flow behavior from both methods. Flow function plots and effective angle of internal friction measurements indicated contiguous trends and showed that the methods were comparable.
\end{abstract}

Keywords: Powders, Flow properties, Ring shear testers, RST, PFT.

\section{INTRODUCTION}

The use of powders or bulk solids in the chemical industry is prodigious. A few years ago it was estimated that around $60 \%$ of all products that were being produced by the chemical industries in a European level were bulk solids, while around $80 \%$ of the products involved bulk solids as ingredients in the processes. ${ }^{[1-3]}$ Powder flow properties are of vital significance in handling and processing industrial operations mainly related to the flow from hoppers and silos, transportation, mixing, compression, and packaging. ${ }^{[4,5]}$ Poor flow properties lead to wastage, machinery maintenance problems, and downtime that greatly influence the profitability of the industrial processes. ${ }^{[2,3]}$ Moreover, different flow properties of constituent powders in mixes may cause variations in mixture homogeneity, which in turn may lead to pack weight, performance, sensory properties, and quality differentiations of the products. ${ }^{[5]}$ In order to overcome these difficulties there is a particular need for defining, understanding, and predicting the flow behavior of the powders and their mixes. Powder flow knowledge can help to design the optimum industrial equipment, storage and transportation conditions, processes, and quality requirements.

Over the last decades several methods and techniques have been proposed for measuring the flow properties of the bulk solids. Jenike was the pioneer in the area of the determination and 
evaluation of powder flow properties, ${ }^{[6]}$ while more recently a variety of techniques and other testers, such as translational, rotational, uniaxial, biaxial, and triaxial, have been proposed. ${ }^{[7]}$ In general, all the available testers may be divided into the main categories of direct and indirect testers. ${ }^{\left[{ }^{8]}\right.}$ Due to the importance of the powder flow properties and the variety of the available measuring methods, several theoretical and experimental studies have been published regarding the comparison and the evaluation of different bulk solids flow properties testers. ${ }^{[3,7,9]}$

Herein, two commercially available shear testers were experimentally compared. The chosen testers were a ring shear tester (RST-XS) from Dr. Dietmar Schulze and a powder flow tester (PFT) from Brookfield Engineering Laboratories Inc. The PFT complies with the test procedure ASTM D6128 using the annular and Jenike shear tests techniques, while the RST with the test procedure ASTM 6773. The RST is a well-established method used in several research studies and industrial measurements, while the PFT is a promising piece of equipment that has been distributed recently and there are not many published studies presenting data acquired from it. The PFT is a newer piece of equipment, and it is, therefore, of interest to compare flow property measurements of the PFT with the RST. For the needs of our study, different food powders were taken into account combining different particle sizes, particle shapes, and hygroscopicity. Several flow data of the tested powders were obtained from both testing methods, such as flow function, effective angle of wall friction, cohesion, bulk density, and effective angle of internal friction under various consolidation stresses. In our study, the evaluation will be based on the comparison of flow function, and the effective angle of internal friction measurements.

Major differences between the equipment are that the PFT is consolidated and controlled from the top plate, whereas the RST shear cell is consolidated by a normal load system with a loading rod and the shear stress is measured from the sides by two shear force transducers. In comparison to the PFT, the bottom shear cell is moved on the RST. In addition, the PFT specimen volume is more than eight times larger than it is for the RST. The basic measurement principle for the RST and PFT is to measure the yield locus of the powder, which represents the stress necessary for the powder to flow after consolidation. A Mohr stress circle represents the stress state in the powder (Fig. 1a) during consolidation and, therefore, it defines the consolidation major principal stress $\sigma_{1}$. Another Mohr circle passing though the origin describes the state of stress under unconfined compression and, therefore, it defines and unconfined yield strength $\sigma_{\mathrm{c}}$. The ratio of the major principal consolidation stress $\sigma_{1}$ and unconfined yield strength $\sigma_{\mathrm{c}}$ defines the flow factor $\left(\mathrm{ff}_{\mathrm{c}}\right) \mathrm{Eq}$. $(1) \cdot{ }^{[1]}$

(a)

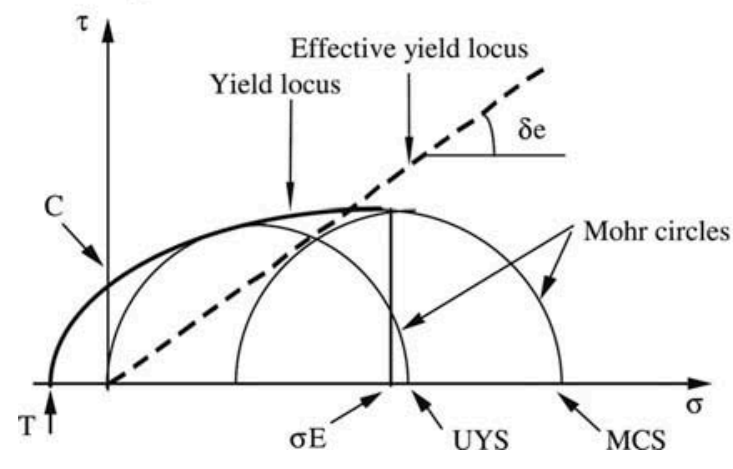

(b)

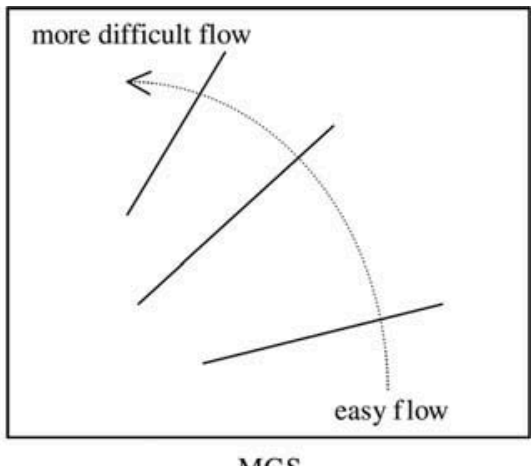

MCS

FIGURE 1 (a) Yield locus and Mohr stress circles in a normal stress $\sigma$, shear stress $\tau$ diagram, where the Mohr stress circles define the consolidations stress $\sigma_{1}$ (MSC) and unconfined yield strength $\sigma_{\mathrm{c}}$ (UYS); (b) Flowability $\mathrm{ff}_{\mathrm{c}}$ presented by flow functions (from [4] with permission). 


$$
f f_{c}=\frac{\sigma_{1}}{\sigma_{c}}
$$

High flowability $\left(\mathrm{ff}_{\mathrm{c}}>10\right)$ means the powder is free-flowing, and low flowability $\left(\mathrm{ff}_{\mathrm{c}}<1\right)$ means the powder is non-flowing. If the flowability is determined for several consolidations stresses, it can be presented in a flow function plot, as shown in Fig. 1b. ${ }^{[1,7]}$ From the yield locus further powder characteristics which can be used to support the silo design can be determined. In Fig. 1a, the effective angle of internal friction $\delta_{\mathrm{e}}$ is shown, represented by the angle of the effective yield locus.

\section{MATERIALS AND METHODS}

\section{Powders}

Four food powders, cumin (Cuminum cyminum L), oregano (Origanum vulgare), onion powder and granulated onion (Allium cepa), were obtained from Santa Maria-Paulig Group, Mölndal, Sweden. The powders selected are representative of the components typically used in a spice mixture. Cumin represents the standard powder similar in shape and size to other spices like, e.g., black pepper powder, paprika, and coriander powder. ${ }^{[5]}$ Oregano represents the dried herbs category of particles which are typically larger in size with distinct shapes. Onion powder and granules represent the small and larger particle size of highly hygroscopic powders. The water activity of each sample was measured with the use of a water activity meter (Pawkit, Decagon, USA). The water activities of the spices during the experiments remained around 0.35.

The particle size distribution of the cumin, onion powders, and onion granules were measured with a laser diffraction particle size analyzer LS 13320 (Beckman Coulter, Krefeld, Germany). A liquid module was used and the spices were measured by dispersing them in isopropanol. The moisture content of the spices was measured with a halogen moisture analyzer HR73 from Mettler Toledo at ambient temperature.

\section{Determination of Flow Properties}

The flow properties of powders of cumin, oregano, onion powder, and granulated onion were determined with the use of a PFT from Brookfield Engineering Laboratories Inc. and a RSTXS (Dr. Dietmar Schulze Schüttgutmesstechnik, Wolfenbüttel, Germany). The powder flow function is a plot of the unconfined failure strength versus the major principal consolidation stress.

A vane lid was used in the PFT measurements of the flow functions of the powders. The flow function tests were undertaken using the $263 \mathrm{~cm}^{3}$ volume shear cell and running the standard flow function test program. This program measures the flow properties over the range of five major principal consolidation stresses in a geometric progression that generates values of around $0.6,1.2$, $2.5,5.0$, and $10 \mathrm{kPa}$. The PFT was connected with a personal computer (PC) provided with Powder Flow Pro V1.2 software. The flow functions of cumin, oregano, onion powder, and onion granules represent the average values of three independent measurements.

For the RST a shear cell type XS-Mr, with a cross section of $24 \mathrm{~cm}^{2}$ and a specimen volume of $30 \mathrm{~cm}^{3}$, was used to measure yield loci for applied consolidation stresses of $\sigma_{1}=2-20 \mathrm{kPa}$. A variety of specimens with 3.5 to $70 \mathrm{~cm}^{3}$ cell volume are also commercially available according to the demands of the experiments. The data was evaluated with software RSV 95 (Dr. Dietmar Schulze Schüttgutmesstechnik, Wolfenbüttel, Germany). All tests were performed in triplicate at ambient temperature. The duration of the measurements in both methods varied with respect to the cohesiveness of the powder, 5-15 and 18-45 min for RST-XS and PFT, respectively. 


\section{RESULTS AND DISCUSSION}

Figure 2a demonstrates the particle size distribution of cumin together with onion powder and onion granules. Cumin had a volume weighted median diameter $\mathrm{x}_{50,3}=127 \pm 32 \mu \mathrm{m}$, whereas the onion powder had $\mathrm{x}_{50,3}=27 \pm 4 \mu \mathrm{m}$, and the onion granules $\mathrm{x}_{50,3}=352 \pm 39 \mu \mathrm{m}$. The particle size distribution of oregano was not possible to measure with the laser scattering technique that was used, but from Shenoy et al. ${ }^{[10]}$ a median diameter of $d(0.5)=1600 \mu \mathrm{m}$ was acquired (same oregano batch used in both trials). Figure $2 \mathrm{~b}$ illustrates that the moisture content of the spices (at ambient temperature) was in the range of 5-10\% for all powders. These results ensured that the tested powders of our study covered a wide range of particle size with low moisture content.

In Fig. 3, a comparison of the flow function plots between the two techniques for each spice is illustrated. Figure 3a demonstrates that the flow curves of cumin from the PFT followed the RST well. No significant difference was seen in flow behavior between the two methods. For oregano, presented in Fig. 3b, the flow behavior was, however, quite different for the two methods. A reason for this could be due to oregano being more flake-like than a powder, and it was, therefore, difficult to perform the measurements in similar ways because of the different geometry of the RST and PFT testing cells. Moreover, during the PFT measurements, oregano showed loss of strength at the beginning of locus \#1, which may have influenced the PFT result. The flow curve of the onion powder (Fig. 3c) was the same for both methods for consolidation stresses up to $5 \mathrm{kPa}$. Above this consolidations stress, the PFT showed a lower flowability of the onion powder than RST. The fine onion powder showed higher failure strength below $10 \mathrm{kPa}$ of consolidation stress, which may be due to different compaction level from the lids of the equipment. The measurements for the onion granules (Fig. 3d) showed the same behavior for both methods. Due to quite a large standard deviation, no significant difference could be seen. The standard deviations of the RST flow functions seemed to be low in all the powders except the highest level of consolidation stress which tended to become more significant. In PFT measurements the standard deviation seemed to be low as well, but in some measurements the standard deviation was randomly larger which is probably related to discrepancies between the prepared samples.

Figure 4 demonstrates the effective angle of internal friction of the spices measured with the PFT and RST. The friction angle differed somewhat more between the methods compared to the flow function and cohesion. The friction angle was consistently somewhat lower for the PFT measurements compared to the RST, except for oregano where the values followed each other well. The lower friction angles for the PFT might be a result of the larger specimen volume.

Figure 5 demonstrates the flow function of the spices measured with (1) RST and (2) PFT. The optimal testing ranges are different for the two methods, which is why the spices were tested for
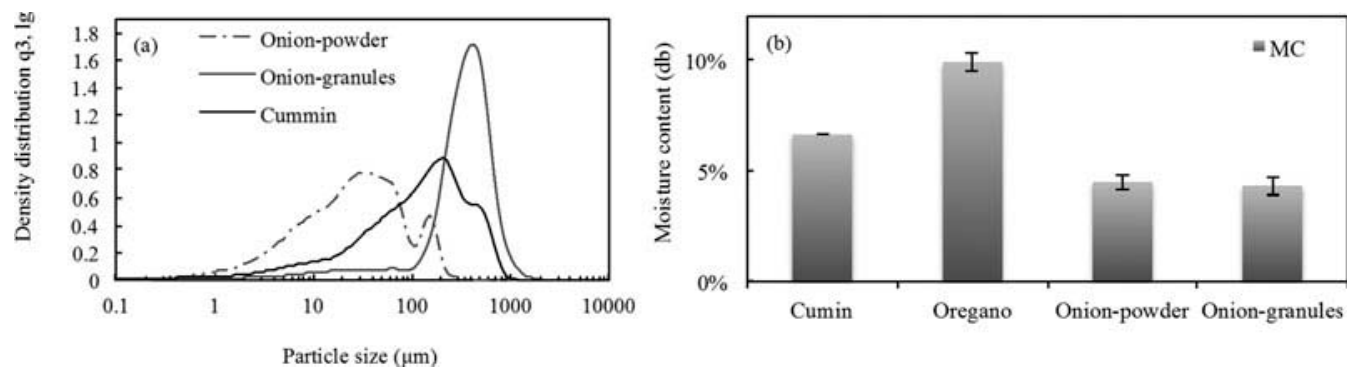

FIGURE 2 (a) Particle size distribution of the onion powder and granules, compared to cumin; and (b) moisture content of the spices at ambient temperature. 

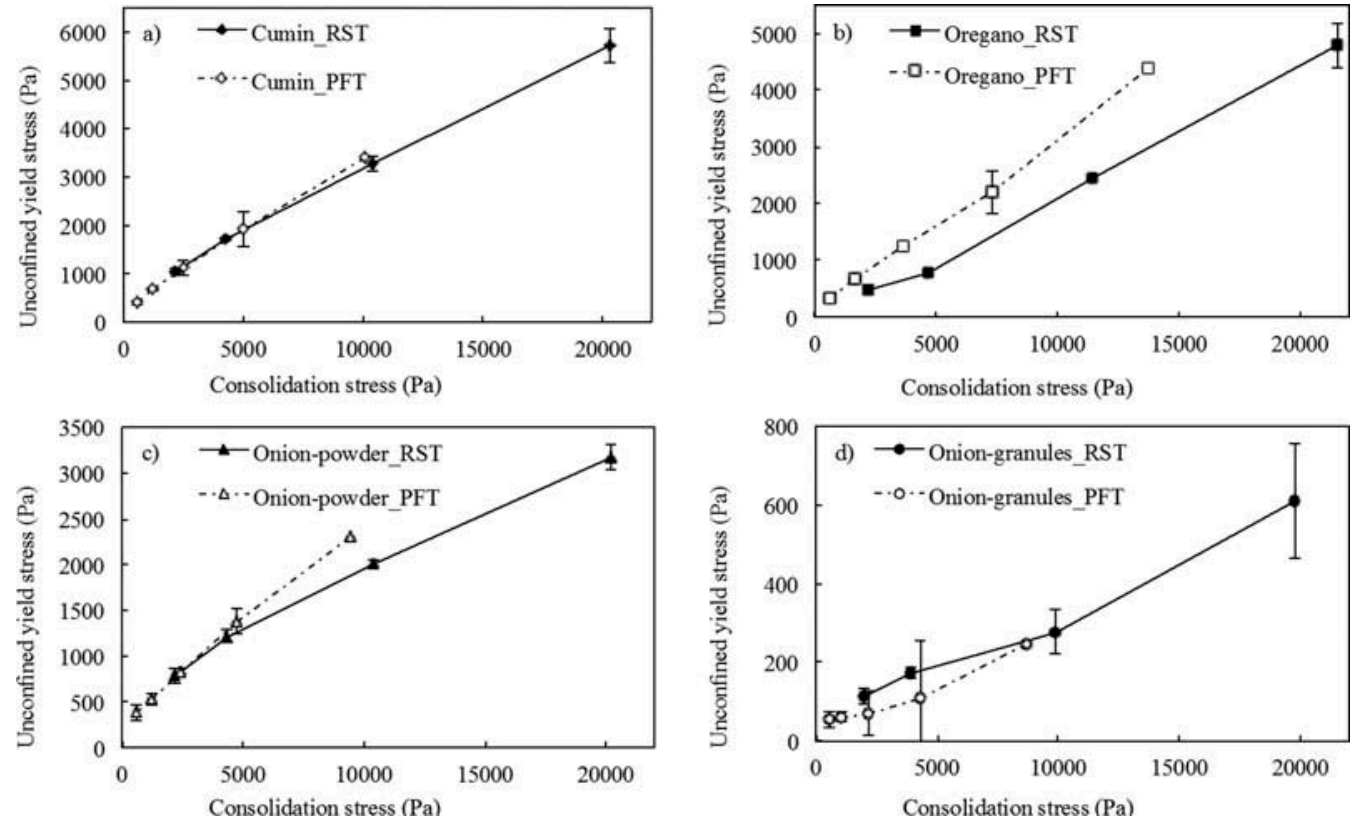

FIGURE 3 Flow function plots of the spices (a) cumin; (b) oregano; (c) onion powder; and (d) onion granules measured with a powder flow tester (PFT) compared to a ring shear tester (RST).
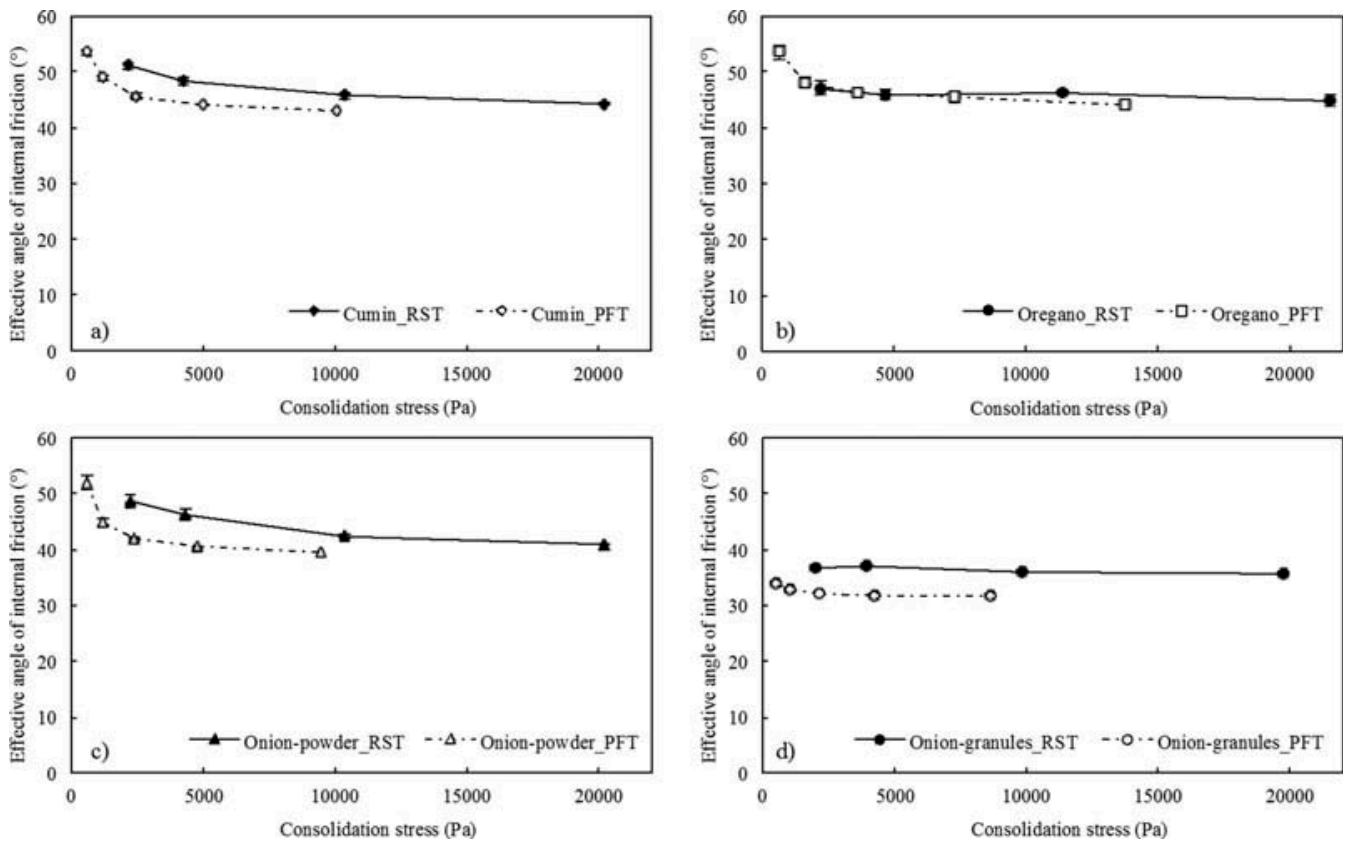

FIGURE 4 Effective angle of internal friction of the spices (a) cumin; (b) oregano; (c) onion powder; and (d) onion granules measured with a ring shear tester (RST) compared to a powder flow tester (PFT). 

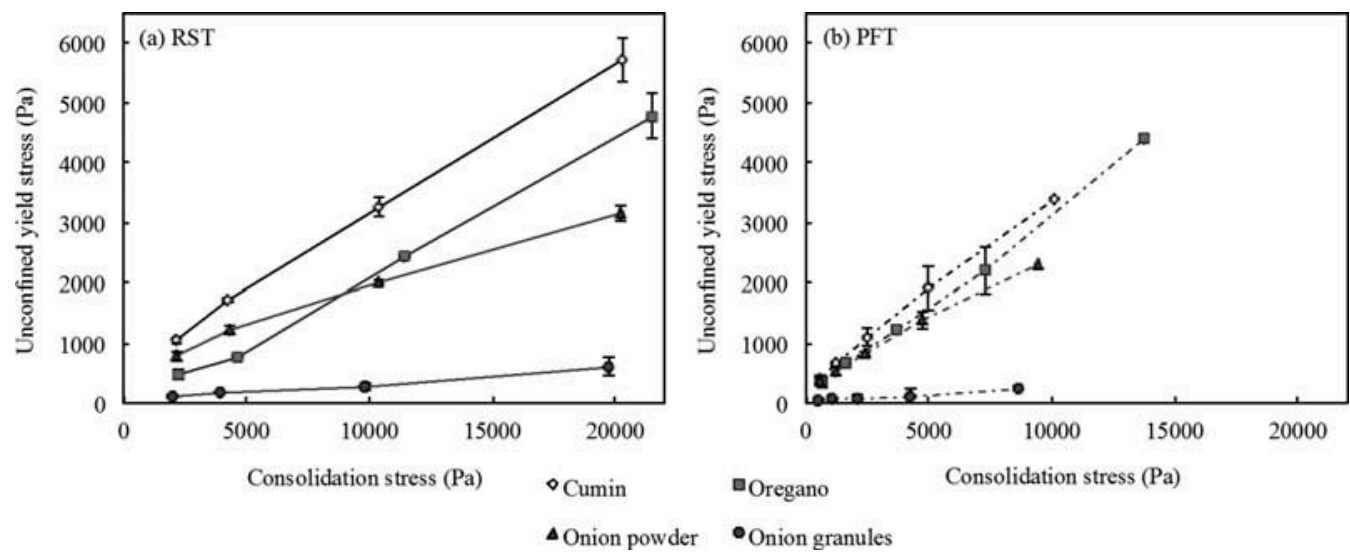

FIGURE 5 Flow function plots of the spices measured with (a) ring shear tester (RST) compared to (b) powder flow tester (PFT).

somewhat higher consolidations stresses with the RST than for the PFT, and vice versa. From both methods it was clear that cumin had the lowest flowability for all tested consolidation stresses, whereas onion granules the highest. The RST measurements in Fig. 5a showed that oregano had higher flowability than onion powder for the lower consolidation stresses. At a consolidation stress around $9 \mathrm{kPa}$ the curves cross, and the opposite was seen, with onion powder having higher flowability. This trend was not seen from the PFT measurements in Fig. 5b, for which onion powder demonstrated similar flowability at low stress values, while at stress levels above $5 \mathrm{kPa}$ showed higher flowability compared to oregano. Although similar pattern and order of the powder's flow function were acquired, the PFT measurements showed lower differences between the powders while the RST indicated more significant differentiations. The flow properties of a powder is highly depending on the consolidation stress. The difference in flowability and friction angle between the powders increased with increasing consolidation stress. The higher consolidations stresses used for the RST measurements might thus explain the larger differentiation that it showed. In addition, the specimen volume might play a role, which was larger for the PFT cell. There is, as well, a difference in how the shear force is measured between the two methods. RST measures shear from the side, which might give somewhat more precise measurements compared to PFT that measures shear from above.

Figure 6 shows the effective angle of internal friction of the spices measured with (1) PFT and (2) RST. The onion granules had the lowest friction angle with both methods. With the RST (Fig. 6a), oregano showed again a different behavior below and above $5 \mathrm{kPa}$, with an increase in friction angle at the higher consolidations stresses. With PFT in Fig. 6b, oregano had consistently the highest friction angle. After oregano, cumin had the highest friction angle for both PFT and RST, followed by onion powder. The effective angle of internal friction calculated in Jenike's mathematical methods is related to the failure properties in the material and it gives an indication regarding the interparticle interactions. ${ }^{[1]}$ More specifically the effective angle of internal friction corresponds to the slope of the effective yield locus (Fig. 1a). Since the larger Mohr circle represents the stresses at steady-state flow, the effective angle of internal friction can be regarded as a measure of the internal friction at steady-state flow. ${ }^{[1]}$ The larger the effective angle of internal friction is, the greater the particle-particle interactions are. Similar results were obtained from both of the methods at high consolidation stresses regarding the particle interactions of the spices. On the other hand, differences were observed at lower levels of consolidation stresses, which may be due to the different number of measurements in that 

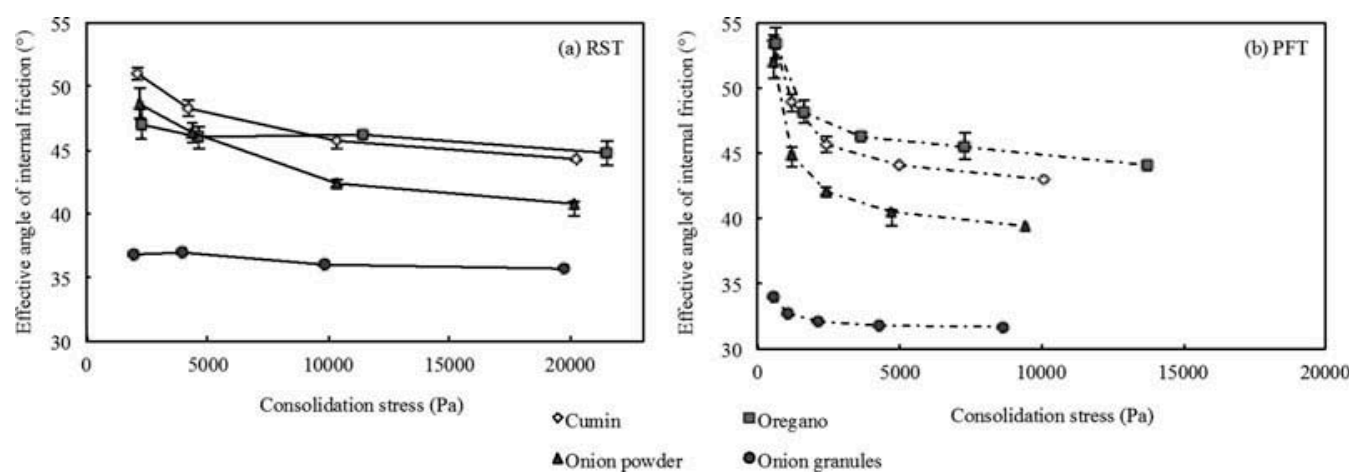

FIGURE 6 Effective angle of internal friction of the spices measured with (a) ring shear tester (RST) compared to (b) powder flow tester (PFT).

range of stress. It can be assumed that PFT is advantageous for measurements at consolidation stresses under $5 \mathrm{kPa}$, while RST measured the flow properties under consolidation stress over 10 $\mathrm{kPa}$. In pharmacy, nanotechnology, ceramics, and other branches of industry where the product quantities are often small, handled with relatively smaller equipment, the powders have to flow under lower consolidation stresses. ${ }^{[12,13]}$ Nevertheless, RST is able to measure also at very low consolidation stresses if the shear cell is specially modified. ${ }^{[12,13]}$

\section{CONCLUSIONS}

In this work, the flow properties of spice powders were measured with PFT (Brookfield) and (Schulze), respectively. The PFT could measure flow at lower consolidation stresses, whereas RST for could be used for higher ones. As a result, somewhat larger differences in flow behavior between the powders was seen for RST compared to the PFT. Oregano showed slightly differing behavior of the flow function, probably due to its flake-like nature, otherwise no major differences were seen in flow behavior for the two methods. Hence, the flow properties measured showed comparable results for the PFT and the RST.

\section{ACKNOWLEDGMENTS}

The authors would like to thank Brookfield Engineering Laboratories Inc. for kindly providing the Brookfield PFT equipment used in this study.

\section{FUNDING}

This work was supported by the E.U. seventh framework program through the "PowTech" Marie Curie Initial Training Network (Project No. EU FP7-PEOPLE-2010-ITN-264722). 


\section{REFERENCES}

1. Schulze, D. Powders and Bulk Solids: Behavior, Characterization, Storage, and Flow; Springer: Berlin, 2008.

2. Juliano, P.; Barbosa-Cánovas, G.V. Food Powders Flowability Characterization: Theory, Methods, and Applications. Annual Review of Food Science and Technology 2010, 1, 211-239.

3. Leturia, M.; Benali, M.; Lagarde, S.; Ronga, I.; Saleh, K. Characterization of Flow Properties of Cohesive Powders: A Comparative Study of Traditional and New Testing Methods. Journal of Powder Technology 2014, 253, 406-423.

4. Fitzpatrick, J.J.; Barringer, S.A.; Iqbal, T. Flow Property Measurement of Food Powders and Sensitivity of Jenike's Hopper Design Methodology to the Measured Values. Journal of Food Engineering 2004, 61, 399-405.

5. Shenoy, P.; Xanthakis, E.; Innings, F.; Jonsson, C.; Fitzpatrick, J.; Ahrné, L. Dry Mixing of Food Powders: Effect of Water Content and Composition on Mixture Quality of Binary Mixtures. Journal of Food Engineering 2015, 149, 229-236.

6. Jenike, A.W. Gravity Flow of Bulk Solids; Utah Engineering. Experiment Station, Bulletin 108: Salt Lake City, Utah, 1961.

7. Schwedes, J. Review on Testers for Measuring Flow Properties of Bulk Solids. Granular Matter 2003, 5, 1-43.

8. Parrella, L.; Barletta, D.; Boerefijn, R.; Poletto, M. Comparison Between a Uniaxial Compaction Tester and a Shear Tester for the Characterization of Powder Flowability. KONA 2008, 26, 178-189.

9. Kamath, S.; Puri, V.M.; Manbeck, H.B.; Hogg, R. Flow Properties of Powders Using Four Testers-Measurement Comparison and Assessment. Journal of Powder Technology 1993, 76, 277-289.

10. Shenoy, P.; Viau, M.; Tammel, K.; Innings, F.; Fitzpatrick, J.; Ahrné, L. Effect of Powder Densities, Particle Size, and Shape on Mixture Quality of Binary Food Powder Mixtures. Journal of Powder Technology 2015, 272, $165-172$.

11. De Campos, M.M.; Ferreira, C. A Comparative Analysis of the Flow Properties Between Two Alumina-Based Dry Powders. Advances in Materials Science and Engineering 2013, 2013, 1-7.

12. Søgaard, S.V.; Pedersen, T.; Allesø, M.; Garnaes, J.; Rantanen, J. Evaluation of Ring Shear Testing As a Characterization Method for Powder Flow in Small-Scale Powder Processing Equipment. International Journal of Pharmaceutics 2014, 475, 315-323.

13. Schulze, D.; Wittmaier, A. Flow Properties of Highly Dispersed Powders at Very Small Consolidation Stresses. Chemical Engineering \& Technology 2003, 26, 133-137. 